1. MBBS, FCPS

\title{
Frequency of short interpregnancy interval in preterm birth.
}

District Gynecologist Obstetrics and

Gynecology

Bacha Khan Medical Complex,

Swabi.

2. MBBS, FCPS

Senior Registrar Obstetrics and

Gynecology

Hayat Abad Medical Complex,

Peshawar.

3. MBBS, FCPS

Assistant Professor Obstetrics and

Gynecology

Bacha Khan Medical Complex,

Swabi.

4. MBBS, FCPS

Assistant Professor Obstetrics and

Gynecology

Mardan Medical Complex, Mardan.

5. MBBS

Resident Gynecologist Obstetrics and Gynecology

Mardan Medical Complex, Mardan.

6. MBBS, DHPM, MScPH

Assistant Professor Community

Medicine

Gajju Khan Medical College, Swabi.

Correspondence Address:

Dr. Jehan Ara

Department of Obstetrics and Gynecology

Bacha Khan Medical Complex, Swabi. Iwb496@gmail.com

Article received on:

23/04/2020

Accepted for publication:

01/12/2020

\section{INTRODUCTION}

Preterm labour (PTL) is characterized when labor happened prior to 37 completed weeks of gestation. ${ }^{1}$ Its predominance has expanded up to "5-7\%" ofamong live births in developed countries. ${ }^{2}$ And hence, it has emerges as a significant cause of neonatal morbidity and mortality and has longterm adverse consequences for infant wellbeing. ${ }^{1}$ PTL is the main cause of approximately 1 million neonatal demises annually. ${ }^{3}$ Developing countries are excessively influenced by PTL and carry a noteworthy burden of disease credited to PTL. ${ }^{3,4}$

Several hazardous factors of PTL are observed. The interim between conceptions is additionally viewed as a hazard factor for PTL and other unfavorable results, for example, preeclampsia, abortion, deformities, cerebral paralysis, intrauterine growth retardation, and perinatal loss or newborn child demise. ${ }^{5}$ Short interpregnancy intervals (IPI) are related with various unpleasant outcomes for both mother and baby, together with high risk of PTL, pregnancy induced hypertension, and low birth weight, that make preclusion of short IPI a priority in the developed nations. ${ }^{6,7}$ The pathophysiology behind adverse impacts of short IPI on pregnancy results are not clearly identified. ${ }^{8} \mathrm{~A}$ few causal speculations have been advanced, such as maternal stress, postpartum hormonal imbalance, and the maternal nutritional depletion theory. ${ }^{8}$ An examination revealed that short IPI were observed in "11.02\%" in femlaes experiencing PTL ( $<37$ weeks). ${ }^{9}$ Furthermore another examination announced that recurrence of short IPI was "9.74\%" in PTL. ${ }^{10}$

The current was designed to find frequency of short interval pregnancy interval in women having preterm labour. A lot of international studies are available with higher frequency of short 
interpregnancy intervals in preterm labour ${ }^{9,10}$ but no local study is available so far to determine local statistics. In our targeted females birth gap has not been controlled so for even with extensive advertisement and awareness from family planning departments. If we find higher frequency of short interpregnancy intervals then in future women with short interpregnancy intervals was managed more vigilantly to prevent preterm labour from their first antenatal visit and additionally their nutritional requirement was considered with medical treatments.

\section{MATERIAL \& METHODS}

\section{Study Design}

This Descriptive cross sectional study was conducted at Department of Obstetrics and Gynecology from 01-07-2018 to 31-12-2018 Bacha Khan Medical Complex Swabi.

The Sampling Technique used was Nonprobability consecutive sampling

The sample size was 212 using $9.74 \%$ frequency of short interpregnancy interval in preterm labour ${ }^{10}$, $95 \%$ confidence level \& $4 \%$ margin of error with WHO software for sample size determination.

All females with age 18-40 years having at least 4 antenatal visits during pregnancy with parity $\geq 1$ having preterm labour were included. All females with gestational DM (diabetes mellitus) and hypertensive disorders, and females having previous preterm labour (on patient's history) were excluded.

After meeting inclusion criteria a total of preterm birth as per operational definition was taken from department of Obstetrics and Gynecology Bacha Khan Medical Complex Swabi. After taking informed consent form females or from their attendants, gestational age, Gravida and Parity was noted of each mother. Their demographical (name, age, address) information was taken. Every subject was requested to provide their information regarding interpregnancy interval in months in current and previous pregnancy. Preterm labour was defined as a gestational age less than 37 completed weeks (was calculated form last menstrual period if available otherwise on ultra-sonography) and Short Interpregnancy interval was defined if the interpregnancy interval between the two pregnancies is estimated as the difference between the date of delivery of the previous child and the date of conception of the second pregnancy. The date of conception was estimated by subtracting the gestational age in weeks from the date of the birth. Short interpregnancy interval was labeled if interval is calculated $\leq 6$ month. All collected data was entered and analyzed using SPSS 22. Quantitative variables like gestational age (weeks) and age (years) parity, gravida was presented in form of mean \pm S. D. Frequency (\%) was used for short inter pregnancy. Data was stratified for maternal age, Gravida, parity \& gestational age, to controls the effect modifier. Post stratified chi-square test was used for effected modifiers. P-value $\leq 0.05$ was considered as significant.

\section{RESULTS}

The mean age of patients in this study was $29.00 \pm 6.37$ years with minimum and maximum ages of 18.00 years and 40.00 years respectively. The mean gestational age among patients was $29.83 \pm 3.29$ weeks with minimum and maximum gestational ages of 24.00 weeks and 36.00 weeks respectively. The mean inter-pregnancy interval observed in this study was $7.39 \pm 6.14$ months with minimum and maximum intervals of 2.00 months and 14.00 months respectively. According to definition, 155 (73.1\%) patients had short interpregnancy interval. Among these patients with short interpregnancy interval, 85 (54.8\%) were in age group of 18-30 years and 70 (45.2\%) were in $31-40$ years of age group. Age groups were statistically associated with interpregnancy interval $(p$-value $=0.04)$. Also, among the patients with short interpregnancy interval, 111 (71.6\%) had $1-3$ parity and $44(28.4 \%)$ had $>3$ parity. Parity was not statistically associated with interpregnancy interval ( $p$-value $=0.181$ ). When the patients with short interpregnancy interval were stratified for gravida, 111 (71.6\%) had 0-2 gravida and 44 (28.4\%) had $>2$ gravida. Gravida was not statistically associated with interpregnancy interval $(p$-value $=0.181)$. Among 
the 155 patients with short interpregnancy interval, $74(47.77 \%)$ had gestational age of 24-29 weeks and 81 (52.3\%) had gestational age of 3036 weeks. Gestational age was not significantly associated with interpregnancy interval ( $p$-value $=$ 0.858).

\begin{tabular}{|c|c|c|c|c|}
\hline & $\begin{array}{c}\text { Age } \\
\text { (years) }\end{array}$ & $\begin{array}{c}\text { Gestational } \\
\text { Age } \\
\text { (weeks) }\end{array}$ & \multicolumn{2}{|c|}{$\begin{array}{c}\text { Interpregnancy } \\
\text { Interval } \\
\text { (months) }\end{array}$} \\
\hline Mean & 29.00 & 29.83 & \multicolumn{2}{|c|}{7.39} \\
\hline S.D & 6.37 & \multicolumn{2}{|l|}{3.29} & 6.14 \\
\hline Range & 22.00 & 12.00 & \multicolumn{2}{|c|}{32.00} \\
\hline Minimum & 18.00 & \multicolumn{2}{|l|}{24.00} & 2.00 \\
\hline Maximum & 40.00 & 36.00 & \multicolumn{2}{|c|}{34.00} \\
\hline \multicolumn{5}{|c|}{$\begin{array}{l}\text { Table-I. Descriptive Statistics of age (years), } \\
\text { gestational age (weeks) and interpregnancy interval. }\end{array}$} \\
\hline & & \multicolumn{2}{|c|}{$\begin{array}{c}\text { Short } \\
\text { Interpregnancy } \\
\text { Interval }\end{array}$} & \multirow[t]{2}{*}{ P- Value } \\
\hline & & Yes & No & \\
\hline \multirow{2}{*}{$\begin{array}{l}\text { Age groups } \\
\text { (years) }\end{array}$} & $18-30$ & $\begin{array}{c}85 \\
(54.8 \%)\end{array}$ & $\begin{array}{c}40 \\
(70.2 \%)\end{array}$ & \multirow{2}{*}{0.004} \\
\hline & $31-40$ & $\begin{array}{c}70 \\
(45.2 \%)\end{array}$ & $\begin{array}{c}17 \\
(29.8 \%)\end{array}$ & \\
\hline \multirow{2}{*}{ Parity } & $1-3$ & $\begin{array}{c}111 \\
(71.6 \%)\end{array}$ & $\begin{array}{c}46 \\
(80.7 \%)\end{array}$ & \multirow{2}{*}{0.181} \\
\hline & $>3$ & $\begin{array}{c}44 \\
(28.4 \%)\end{array}$ & $\begin{array}{c}11 \\
(19.3 \%)\end{array}$ & \\
\hline \multirow{2}{*}{$\begin{array}{l}\text { Gestational } \\
\text { Age (weeks) }\end{array}$} & $24-29$ & $\begin{array}{c}74 \\
(47.7 \%)\end{array}$ & $\begin{array}{c}28 \\
(49.1 \%)\end{array}$ & \multirow{2}{*}{0.858} \\
\hline & $30-36$ & $\begin{array}{c}81 \\
(52.3 \%)\end{array}$ & $\begin{array}{c}29 \\
(50.9 \%)\end{array}$ & \\
\hline
\end{tabular}

Table-Il. Comparison of Short interpregnancy interval when stratified for age (years), parity and gestational age (weeks).

\section{DISCUSSION}

The worldwide prevalence of preterm birth (PTB) is " $9.6 \%$ " and the rate of PTB in Pakistan is reported as "15.7\%" while it is "6.6\%" in Australia. PTB is one of the significant contributing factors causing infant morbidity and mortality. 2,11,12

\section{Short interpregnancy interval}

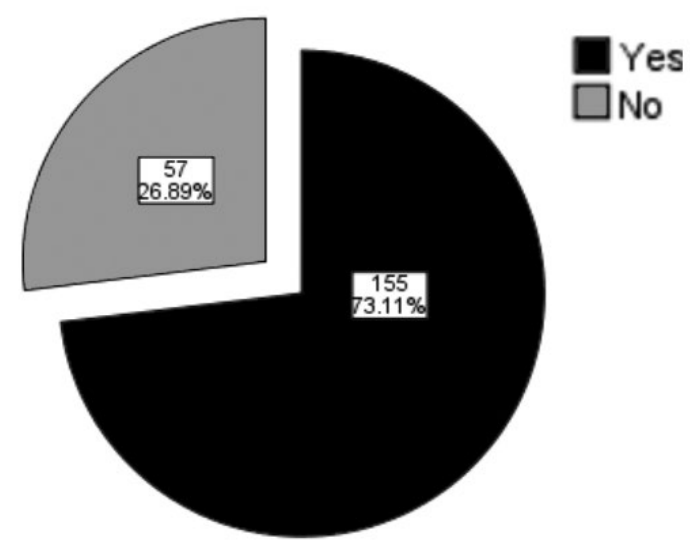

Figure-1. Distribution of short interpregnancy interval.

Evidently, there is no commonly acknowledged clarification for the high danger of unfavorable pregnancy result after short IPI. There is a high danger of folate inadequacy at conception time and during pregnancy in females who become pregnant with short interim. As a result, their infants have higher dangers of neural tube defects, intrauterine growth retardation and PTB. ${ }^{13}$

In the couple of studies that have been led of the association between short and long IPI and unfavorable perinatal results, no definite inferences could be portrayed due to methodological limitations or small number of cases. $^{14-16}$

Henceforth, due to complicated association observed in the IPI with PTB and expanding rate of PTB in Pakistan; it is important to observationally address the problem immediately. Along these lines, we led this investigation to decide frequency of short IPI in women with PTL.

The basic demographic characteristics of our patients were comparable with other studies. The mean age of patients in this study was $29.00 \pm 6.37$ years with minimum and maximum ages of 18.00 years and 40.00 years respectively. The mean parity in this study was observed to be $3.23 \pm 2.31$ with minimum and maximum parity of 1 and 9 respectively. The mean gravida in this study was 
$2.17 \pm 2.25$ with minimum and maximum of 0 and 8. The mean gestational age among patients was $29.83 \pm 3.29$ weeks with minimum and maximum gestational ages of 24.00 weeks and 36.00 weeks respectively. Shaikh K. et al, conducted an investigation to assess the relationship between parity, gender, higher paternal education and PTB in Pakistan with median age of subjects in term births was 26 years and in PTB group was 27 years. There were " $41 \%$ " primiparous parity in term versus "20\%" in PTB groups; though, "59\%" multiparous parity in term versus " $80 \%$ " in PTB groups. Additionally, in there were no baby in $20 \%$ subjects, $1-2$ in $66.7 \%$ and $>2$ in $13.3 \%$ in PTB group and there were no baby in $45.3 \%$ subjects, $1-2$ in $43.6 \%$ and $>2$ in $11.1 \%$ in term group. ${ }^{17}$

One examination concluded if a short interval between pregnancies is an independent hazard factor for unfavorable obstetric result. They chose 89,143 females having $2^{\text {nd }}$ births in $1992-8$ who become pregnant within 5 years of their first child. $91.6 \%$ subjects were found to be in age of 20-35 years, while $5.2 \%$ were more than 35 years old and $3.2 \%$ were less than 20 years old. Among those, when the patients age with IPI of 6-11 months was stratified, there were " $87.8 \%$ " female in "20-35" years age, "4.8\%" in > 35 years old and "7.4\%" in <20 years. Additionally, in IPI of 12 to 17 months, there were "91\%" females in 20-35 years age, " $4.9 \%$ " in $>35$ years old and " $4.1 \%$ " in $<20$ years. ${ }^{18}$ They likewise detailed that females whose resulting IPI was under a half year were almost certain than other females to have had a $1^{\text {st }}$ birth entangled by intrauterine growth restriction (odds ratio $(\mathrm{OR}) 1.3,95 \%$ confidence interval $(\mathrm{Cl}) 1.1$ to 1.5), extremely preterm birth (EPTB) $(4.1,3.2$ to $5.3)$, moderately PTB $(1.5,1.3$ to 1.7$)$, or perinatal loss $(24.4,18.9$ to 31.5$)$. On the other hand, a short IPI (< a half year) was an independent hazard factor for EPTB (adjusted odds ratio; 2.2, 1.3 to 3.6$)$, moderately PTB (1.6, 1.3 to 2.0$)$, and infant death irrelevant to congenital abnormality (3.6, 1.2 to 10.7). ${ }^{18}$ Also, like our investigation results, when the result of the $2^{\text {nd }}$ birth was examined comparable to the former IPI and the examination kept to females whose $1^{\text {st }}$ birth was a term live birth ( $n=69$ 055), no noteworthy relationship observed (adjusted for age, stature, conjugal status, financial status, smoking, past birth weight and past cesarean section) between IPI and stillbirth or intrauterine growth restriction. ${ }^{18}$ These findings are comparable with current study. In current study 155 (73.1\%) patients had short inter-pregnancy interval. Among the 155 patients with short interpregnancy interval, 74 (47.77\%) had gestational age of 24-29 weeks and 81 (52.3\%) had gestational age of 30-36 weeks. Gestational age was not significantly associated with interpregnancy interval $(p$-value $=0.858)$. While stratified for other variables, we found that parity, gravida and gestational ages were insignificant with IPI however age had statistical significance with IPI ( $p$-value=0.04). Our study indicates, however, that frequency of pre-term birth was very frequent with short IPI though not statistically significant. Similar results have been published earlier as well. One investigation in 1977-1980, cross-examined more than 12,000 pregnant females who were followed up at the Boston Hospital for Women and had their clinical records looked into. The impact of IPI on the chances of PTL was evaluated in 4,467 of these females whose past pregnancy had brought about a full-term live birth. The chance of PTB after the spontaneous onset of labor in this study was $3.8 \%$, whereas the chance of an expanded danger of PTL for IPI of 3 months or less can't be certainly excluded (adjusted odds ratio $=2.0$, 95\% Cl 0.7-5.4), no connection was establish between other IPI and the risk of PTL. ${ }^{16}$

This demonstrates short IPI stays an impending danger for adverse maternal and perinatal results and hence ought to be forestalled. One investigation inspected the relationship between small for gestational age (SGA) birth at term and IPI in a medical clinic cohort of 4489 multiparous females. The most serious danger of SGA birth was observed in females with the briefest IPI. Much subsequent to altering for various confounding factors, females whose IPI was 18 or less months (more than $33 \%$ of ladies in the cohort) were at double risk of bringing forth a term SGA baby when contrasted with females IPI was 24 to 36 months. In a logistic regression analysis assessing the frequency of SGA birth in females with IPI of 
three years or less, a strong linear relationship was recorded between these two components. ${ }^{19}$ However, one more investigation indicated that short IPI ( $\leq 8$ months) were related with PTB but not with low birth weight. The adjusted OR for PTB were 3.60 (95\% Cl 2.04 to 6.35) for adjusted up to 4.00 months and 2.28 (1.49 to 3.48) for adjusted somewhere in the range of 4.01 and 8.00 months contrasted with deliveries following 24 to 36 months, having the risk of PTB was $3.5 \%$. The chances were higher in females with a past pregnancy at term, financial wellbeing, age, and parity were adjusted for. ${ }^{20}$ Studies have additionally stratified the early versus late PTB to investigate the impact of short IPI on each one of these stages. In 2008, an examination proclaimed that there was a critical relationship between short IPI and spontaneous early PTB, both crude (OR $=3.9 ; 95 \% \mathrm{Cl}: 1.91-8.10)$ and adjusted for age of mother, education, past birth results, antenatal visits, smoking, body mass index and gestational weight gain (adj OR $=3.6 ; 95 \% \mathrm{Cl}$ : 1.41-8.98). No considerable impact on spontaneous late PTB was noted (crude OR $=0.8 ; 95 \% \mathrm{Cl}$ : 0.32-1.83)..$^{21}$ De Franco E.A., et al., likewise revealed that short IPIs ( $<6$ months) magnified the risk of extreme PTB (adj OR, 1.41; 95\% Cl, 1.13-1.76). IPIs of less than 6 months and 6 to 12 months expanded the risk of PTB (adj OR, 1.48 [95\% Cl, 1.37-1.61] and 1.14 [95\% Cl, 1.06-1.23], separately) and PTB recurrence (balanced chances proportions, 1.44 [95\% Cl, 1.19-1.75] and 1.24 [95\% Cl, 1.02-1.50], individually). ${ }^{22}$

\section{CONCLUSION}

Through this study we found high frequency of short inter pregnancy interval. We must have to establish more and effective family planning awareness to increase birth gap to avoid poor fetomaternal outcome as it is clear that short IPI may directly or indirectly influence the maternal and perinatal health and can potentially increase risk of preterm birth.

Copyright@ 01 Dec, 2020.

\section{REFERENCES}

1. Beck S, Wojdyla D, Say L, Betran AP, Merialdi M, Requejo $\mathrm{JH}$, et al. The worldwide incidence of preterm birth: A systematic review of maternal mortality and morbidity. Bull WHO. 2010; 88(1):31-8.
2. Black RE, Cousens S, Johnson HL, Lawn JE, Rudan I, Bassani DG, et al. Global, regional, and national causes of child mortality in 2008: A systematic analysis. The Lancet. 2010; 375(9730):1969-87.

3. Simmons LE, Rubens CE, Darmstadt GL, Gravett MG. Preventing preterm birth and neonatal mortality: exploring the epidemiology, causes, and interventions. Seminars in perinatol. 2010; 34(6):40815.

4. Bortolus R, Blom F, Filippini F, van Poppel MN, Leoncini E, de Smit DJ, et al. Prevention of congenital malformations and other adverse pregnancy outcomes with $4.0 \mathrm{mg}$ of folic acid: Communitybased randomized clinical trial in Italy and the Netherlands. BMC. 2014; 14(1):166-81.

5. Gemmill A, Lindberg LD. Short interpregnancy intervals in the United States. Obs \& Gynecol. 2013; 122(1):64-71.

6. Conde $\square$ Agudelo A, Rosas $\square$ Bermudez A, Castaño F, Norton $\mathrm{MH}$. Effects of birth spacing on maternal, perinatal, infant, and child health: A systematic review of causal mechanisms. Stud Fam Plan. 2012; 43(2):93-114.

7. Smits LJ, Elzenga HM, Gemke RJ, Hornstra G, van Eijsden $\mathrm{M}$. The association between interpregnancy interval and birth weight: What is the role of maternal polyunsaturated fatty acid status? BMC. 2013; 13(1):23-31.

8. Rodrigues $\mathrm{T}$, Barros $\mathrm{H}$. Short interpregnancy interval and risk of spontaneous preterm delivery. Eur $\mathrm{J}$ Obstet Gynecol Reprod Biol. 2008; 136(2):184-8.

9. Grisaru-Granovsky S, Gordon E-S, Haklai Z, Samueloff A, Schimmel MM. Effect of interpregnancy interval on adverse perinatal outcomes-a national study. Contraception. 2009; 80(6):512-8.

10. Lawn JE, Gravett MG, Nunes TM, Rubens CE, Stanton C. Global report on preterm birth and stillbirth (1 of 7): definitions, description of the burden and opportunities to improve data. BMC pregnancy and childbirth. 2010; 10(1):1.

11. Goldenberg RL, Culhane JF, lams JD, Romero R. Epidemiology and causes of preterm birth. The Lancet. 2008; 371(9606):75-84.

12. Smits LJ, Essed GG. Short interpregnancy intervals and unfavorable pregnancy outcome: role of folate depletion. The lancet. 2001; 358(9298):2074-7. 
13. Adams M, Delaney K, Stupp P, McCarthy B, Rawlings $J$. The relationship of interpregnancy interval to infant birthweight and length of gestation among low-risk women, Georgia. Paediatric and Perinatal Epidemiology. 1997; 11(S1):48-62.

14. Klerman LV, Cliver SP, Goldenberg RL. The impact of short interpregnancy intervals on pregnancy outcomes in a low-income population. American Journal of Public Health. 1998; 88(8):1182-5.

15. Lang JM, Lieberman E, Ryan KJ, Monson RR. Interpregnancy interval and risk of preterm labor. American Journal of Epidemiology. 1990; 132(2):304-9.

16. Shaikh K, Premji SS, Rose MS, Kazi A, Khowaja S, Tough $S$. The association between parity, infant gender, higher level of paternal education and preterm birth in Pakistan: a cohort study. BMC pregnancy and childbirth. $2011 ; 11(1): 1$.

17. Smith GC, Pell JP, Dobbie R. Interpregnancy interval and risk of preterm birth and neonatal death: retrospective cohort study. Bmj. 2003; 327(7410):313.
18. Lieberman E, Lang JM, Ryan KJ, Monson RR, Schoenbaum SC. The association of inter-pregnancy interval with small for gestational age births. Obstetrics \& Gynecology. 1989; 74(1):1-5.

19. Basso O, Olsen J, Knudsen LB, Christensen K. Low birth weight and preterm birth after short interpregnancy intervals. American journal of obstetrics and gynecology. 1998; 178(2):259-63.

20. Rodrigues $\mathrm{T}$, Barros $\mathrm{H}$. Short interpregnancy interval and risk of spontaneous preterm delivery. European Journal of Obstetrics \& Gynecology and Reproductive Biology. 2008; 136(2):184-8.

21. DeFranco EA, Stamilio DM, Boslaugh SE, Gross GA, Muglia LJ. A short interpregnancy interval is a risk factor for preterm birth and its recurrence. American journal of obstetrics and gynecology. 2007; 197(3):264. e1-. e6.

\begin{tabular}{|c|l|l|l|}
\hline \multicolumn{3}{|c}{ AUTHORSHIP AND CONTRIBUTION DECLARATION } \\
\hline Sr. \# & \multicolumn{1}{|c|}{ Author(s) Full Name } & Contribution to the paper & Author(s) Signature \\
\hline 1 & Jehan Ara & 1st Author \\
\hline 2 & Maryam Khan Badshah & 2nd Author \\
\hline 3 & Surraya Israr & 3rd Author \\
\hline 5 & Hemasa Gul & 4th Author \\
\hline 6 & M. Khalid Khan & 5th Author & \\
\hline
\end{tabular}

